\title{
Location and course of the mandibular canal in dentate patients: morphometric study using cone-beam computed tomography
}

\author{
A. Arias ${ }^{1,2}$, C. Venegas ${ }^{3}$, N. Soto ${ }^{4}$, I. Montiel ${ }^{3}$, C. Farfán ${ }^{1}$, P. Navarro1, 5, R. Fuentes ${ }^{1}$ \\ ${ }^{1}$ Research Centre for Dental Sciences (CICO), Department of Integral Adults Dentistry, Dental School, \\ Universidad de La Frontera, Temuco, Chile \\ ¿Universidad Adventista de Chile, Chillán, Chile \\ 3Undergraduate Student, Dental School, Universidad de La Frontera, Temuco, Chile \\ ${ }^{4}$ Dental School, Universidad de La Frontera, Temuco, Chile \\ ${ }^{5}$ Universidad Autónoma de Chile, Temuco, Chile
}

[Received: 30 July 2019; Accepted: 26 August 2019]

Background: The morphometric characteristics of the mandibular canal (MC) may vary according to the characteristics of the population studied. Correct location of the MC is fundamental for the indication and planning of different dental treatments, and it is therefore essential to have clinical parameters indicating its approximate location. The aim of this study was to describe the location and course of the MC by morphometric relations in the mandibular body, from the mental foramen to distal of the first molar, in dentate adult patients.

Materials and methods: We analysed 55 cone-beam computed tomography (CBCT) of male and female patients, aged over 18 years and with fully dentate to the first molar. In each CBCT we selected five coronal sections $(A-E)$ of the mandibular body at different levels using the teeth as references. We determined different morphometric measurements in each section to relate the $M C$ with the corticals of the mandibular body $(m 1, m 2, m 3, m 4)$, their orientation to lingual (F) and the thickness of the mandibular corticals (B1, B2 and B3).

Results: The distance between the MC and the alveolar crests was greater in males than in females in all the sections. In general, in all the hemiarches, the $M C$ courses away from the vestibular cortical of the mandible (and in some cases significantly towards the lingual cortical) from anterior to posterior in the mandibular body. In the left hemiarch of dentate females the MC describes a descent in the molar zone within the mandibular body. Any intervention in the mandible must be carried out with extreme caution to avoid damaging the vasculo-nervous bundle which passes through the MC.

Conclusions: Cone-beam computed tomography is the best tool currently available for the planning and execution of surgical procedures, and is the only tool in clinical use which allows the precise course of the MC to be identified. (Folia Morphol 2020; 79, 3: 563-569)

Key words: mandibular canal, cone-beam computed tomography, Chilean population, localisation

Address for correspondence: Prof. Dr. R. Fuentes Fernández, Research Centre for Dental Sciences, Dental School, Universidad de La Frontera, Av. Francisco Salazar 01145, Temuco, Chile, tel: +56 45 2596902, e-mail: ramon.fuentes@ufrontera.cl 


\section{INTRODUCTION}

The mandible is an uneven, mobile bone, located in the inferior posterior part of the face. It provides the seating of the inferior teeth, and together with the hyoid bone it forms the skeleton of the floor of the anatomical mouth [5]. It is considered to consist of three parts: a medial part, the body; and two lateral parts, the rami. The mandibular canal (MC) crosses the body and ramus on each side of the mandible. This conduit originates in the medial face of the mandibular ramus and courses to inferior and anterior, describing an anterior superior curve. It may constitute a conduit with well-defined walls, or describe a trajectory through the trabeculae formed of spongy bone tissue [20].

Due to the MC's anatomical location, relations and variations, its integrity may be altered during different dental procedures, such as third molar surgery, endodontics or osseointegrated implants, causing damage to the nervous and vascular elements contained in the canal [19]. Results of different studies confirm that some anatomical characteristics of the MC are variable, depending on the population studied [21]. These morphological variations in the MC were described decades ago, and range from the presence of bifurcate, trifurcate and even accessory canals to variations in their form, size and position [8, 9, 14, 17].

Correct location of the MC is fundamental for indication, planning and prognosis of different dental treatments, and can be effected using different imaging techniques which provide relevant information and allow variations of the MC to be detected in good time. It is important to preserve the integrity of the MC because it contains the vasculo-nervous bundle which is responsible for the irrigation and sensory activity of the mandibular tissues, such as the lips, gums and teeth $[8,13]$. Cone-beam computed tomography $(\mathrm{CBCT})$ offers a three-dimensional (3D) reproduction of the area studied [24], and therefore allows precise diagnoses for implant operations, assessment of pathologies and periodontal lesions, endodontics, etc. [15]. Knowledge of both "normal" mandibular morphology and the "variations" which may occur is indispensable for correct dental practice [19]. In this field, it is also indispensable to have clinical or intraoral references to allow the approximate location of the MC in the mandibular body to be estimated. The object of the present study was therefore to describe the location and course of the $\mathrm{MC}$ by morphometric relations within the mandibular body, from the mental foramen to distal of the first molar, by CBCT examination, using the teeth of adult subjects with continuous dental arches as a reference.

\section{MATERIALS AND METHODS}

This is a descriptive, retrospective, cross-sectional study in 55 CBCTs of patients attended at the Dental Teaching Clinic of Universidad de La Frontera (Temuco, Chile). The study was approved by the Scientific Ethics Committee (CEC) of Universidad de La Frontera (Folio no. 015/2014). The identities of the patients were not revealed and the only information provided was their age and sex. The images were taken as part of the diagnosis and planning of dental treatment of these patients, using a PAX Zenith 3D tomograph (Vatech Co., Gyeonggi-Do, Korea) with 120 kV, 9 mA, field of view $12 \times 9 \mathrm{~cm}$ and voxel size $0.12 \mathrm{~mm}$. The following inclusion criteria were applied: male and female patients, aged over 18 years and with permanent dentition complete to the first molar in each mandibular hemiarch. The following were exclusion criteria: patients with signs of orthognathic surgery, presence of mandibular implants, presence of pathological mandibular lesions or periapical lesions which compromised the view of any segment of the mandibular canal.

The measurements were taken with the CBCT software and carried out by two previously trained examiners, with a specialist in dentomaxillofacial radiology. The examiners were calibrated by repeated independent measurement of $10 \%$ of the total sample and calculation of the intraclass correlation coefficient (ICC).

Multi-plane reconstructions of the $C B C T$ of each hemiarch were used and the MC identified in each. First of all, the position of the occlusive plane with respect to the horizontal was rectified in sagittal view (Fig. 1A), while the entrance of the mental foramen was located and the sagittal axis was rectified to pass through this foramen and the lingula (vestibulo-lingual orientation from mesial to distal; Fig. 1B). Using a tool in the CBCT software, the $M C$ was defined throughout its course by three specific points (mental foramen, curve of the loop of the mentonian nerve and prior to the loop) and 4 to 5 equidistant points in the canal towards the lingula (Fig. 1C).

To establish the relations and morphometric measurements of the $M C$, the entrance of the mental foramen was located in the axial view of the CBCT, and cross-sections of its course were taken using the "curve" tool. The sections were taken with a thickness of $1 \mathrm{~mm}$ and at $1 \mathrm{~mm}$ intervals. The points defining 


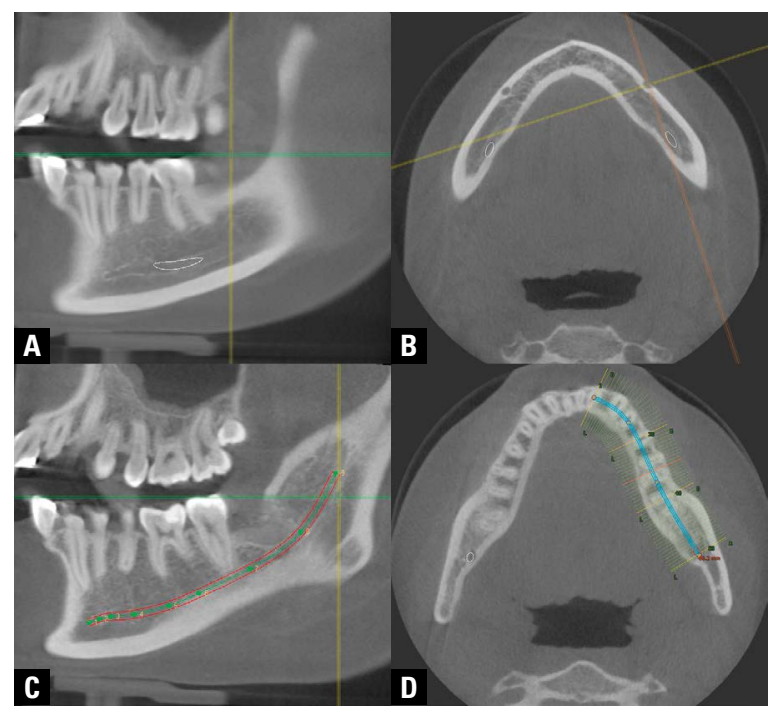

Figure 1. Rectification of the sagittal (A) and axial (B) planes of the cone-beam computed tomography. The measurements were taken in the resulting image of the coronal plane after the rectifications. Definition of the course of the mandibular canal (C). Use of the "curve" tool to carry out cross-sections in the course of the mandibular canal (D).

the position of the mandibular canal were rectified in each coronal section (Fig. 1D). Then the following coronal sections were selected to establish specific morphometric measurements:
- section A: long axis of the second premolar (Fig. 2A);

- section B: interradicular zone of the second premolar and first molar (Fig. 2B);

- section C: long axis of the mesial root of the first molar (Fig. 2C);

- section D: sulcus zone of the first molar (Fig. 2D);

- section E: distal of the first molar (Fig. 2E). Finally, the following morphometric measurements were determined in each of these sections (Fig. 3):

- m1: distance between the most superior point of the cortical of the MC and the projection of the alveolar crests;

- m2: distance between the most vestibular point of the $\mathrm{MC}$ and the vestibular mandibular ridge;

- m3: distance between the most lingual point of the $\mathrm{MC}$ and the lingual mandibular ridge;

- m4: distance between the most inferior point of the $\mathrm{MC}$ and the basal mandibular ridge;

- F: angle formed by the straight lines of measurements $\mathrm{m} 1$ and $\mathrm{m} 3$;

- thickness of the vestibular (B1), lingual (B2) and basal (B3) corticals of the mandibular body.

\section{Statistical analysis}

The data were recorded in a Microsoft Office Excel spreadsheet. Descriptive analysis of the data

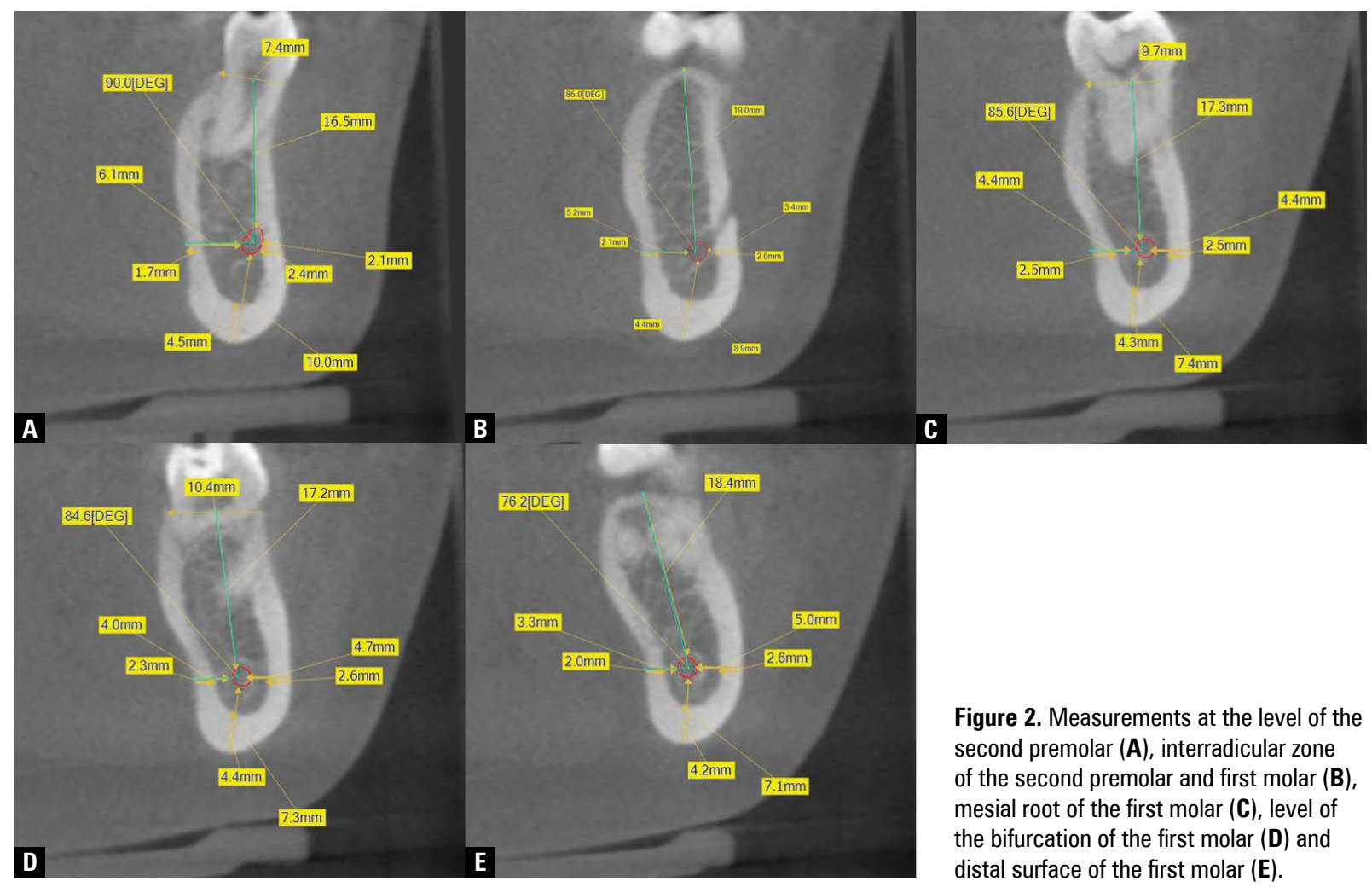




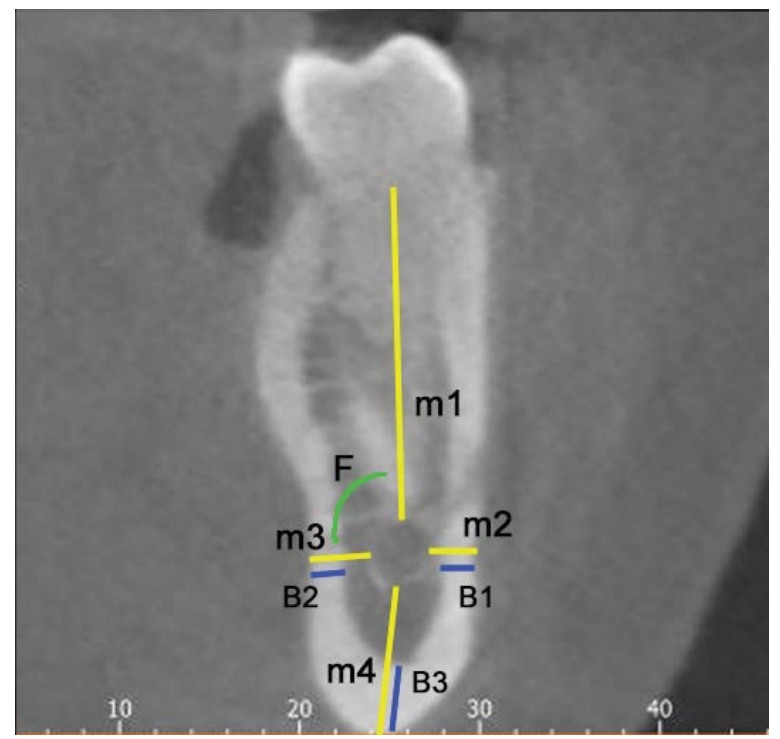

Figure 3. Morphometric measurements on each coronal section of mandibular body (through mandibular canal course).

Table 1. Location of the coronal sections carried out in the course of the mandibular canal (MC) in the mandibular body. The table shows the mean distance of the sections from the mental foramen (emergence of the $\mathrm{MC}$ ), grouped according to whether they are to mesial or distal of the foramen, or coincide with it (distance $0 \mathrm{~mm}$ ). It also shows the number of cases or hemiarches in which each section was to mesial or distal of the mental foramen, or coincident with it

\begin{tabular}{|c|c|c|c|}
\hline \multirow{2}{*}{$\begin{array}{l}\text { СВCT } \\
\text { section }\end{array}$} & \multicolumn{3}{|c|}{ Location of the section relative to the mental foramen } \\
\hline & To mesial & $\begin{array}{c}\text { Coincident } \\
\text { (distance } 0 \mathrm{~mm} \text { ) }\end{array}$ & To distal \\
\hline Section A & $\begin{array}{c}4.38 \pm 2.23 \mathrm{~mm} \\
\mathrm{n}=36\end{array}$ & $\mathrm{~N}=24$ & $\begin{array}{c}3.77 \pm 2.32 \mathrm{~mm} \\
\mathrm{n}=40\end{array}$ \\
\hline Section B & $\begin{array}{c}2.78 \pm 1.57 \mathrm{~mm} \\
\mathrm{n}=14\end{array}$ & $N=8$ & $\begin{array}{c}5.76 \pm 3.08 \mathrm{~mm} \\
\mathrm{n}=78\end{array}$ \\
\hline Section C & $\begin{array}{l}2 \mathrm{~mm} ; \\
\mathrm{n}=1\end{array}$ & $N=3$ & $\begin{array}{c}9.96 \pm 4.37 \mathrm{~mm} ; \\
\mathrm{n}=96\end{array}$ \\
\hline Section D & $N=0$ & $N=0$ & $\begin{array}{c}13.09 \pm 4.75 \mathrm{~mm} \\
\mathrm{n}=100\end{array}$ \\
\hline Section $\mathrm{E}$ & $N=0$ & $N=0$ & $\begin{array}{c}18.41 \pm 4.78 \mathrm{~mm} ; \\
\mathrm{n}=100\end{array}$ \\
\hline
\end{tabular}

CBCT — cone-beam computed tomography

was carried out to determine the means and standard deviations. The Kolgomorov-Smirnov normality test, the t-test for independent samples, ANOVA and post hoc tests of Bonferroni and Tukey were applied. The Mann-Whitney $U$ test for independent samples was also applied, and the Kruskal-Wallis test for the ANOVA. The data were analysed using the IBM
SPSS Statistics Programme (version 23.0). A value of $p<0.05$ was selected as the threshold of statistical significance.

\section{RESULTS}

The sample included 55 CBCTs of patients (22 male and 33 female) with mean age $27 \pm 10.43$ years (25.64 \pm 10.46 years for males, $27.91 \pm 10.47$ years for females). 52 right and 48 left mandibular hemiarches were examined. In the analysis of inter-examiner concordance, the ICC was $99 \%$ (very good). Table 1 summarises the data describing the location of each coronal section $(A, B, C, D$, and $E$ ) in the course of the $M C$ within the mandibular body. Table 2 summarises the means of the different measurements $(\mathrm{m} 1, \mathrm{~m} 2$, $m 3, m 4, B 1, B 2, B 3$, and $F$ ) in each coronal section analysed (A, B, C, D, E), grouped by sex and side of the mandible.

\section{Analysis of the morphometric relations of the MC in the mandibular body in the same coronal section}

In section A (long axis of the second premolar), the mean value of $\mathrm{m} 1$ (distance to superior of the MC) was significantly greater in males than in females $(p=0.003)$. For the rest of the measurements $(\mathrm{m} 2$, $m 3, m 4, F, B 1, B 2$, and B3), no significant differences were found between males and females $(p=0.911$, $p=0.145, p=0.130, p=0.238, p=0.405, p=0.065$, and $p=0.012$, respectively).

In section B (interradicular zone of the second premolar and first molar), the mean values of $\mathrm{m} 1$, $\mathrm{m} 3$ (distance to lingual of the MC), m4 (distance to inferior of the MC) and B2 (thickness of the mandibular lingual cortical) were significantly greater in males than in females $(p=0.001, p=0.002$, $p=0.002$ and $p=0.004$, respectively). For the rest of the measurements (m2, F, B1, and B3), no significant differences were found between males and females $(p=0.077, p=0.178, p=0.530$, and $p=0.255$, respectively).

In section $C$ (long axis of the mesial root of the first molar), the mean values of $m 1, m 3, m 4$ and B3 (thickness of the mandibular basal cortical) were significantly greater in males than in females $(p=0.000$, $p=0.050, p=0.007$ and $p=0.034$, respectively). On the other hand, the mean value of $\mathrm{m} 2$ (distance to vestibular of the $\mathrm{MC}$ ) was greater in females than in males $(p=0.039)$. For the rest of the measurements (F, B1 and B2), no significant differences were found 
Table 2. Mean and standard deviation of the measurements ( $\mathrm{m} 1, \mathrm{~m} 2, \mathrm{~m} 3, \mathrm{m4}, \mathrm{B} 1, \mathrm{~B} 2, \mathrm{~B} 3$, and F) in each of the different coronal sections carried out in the course of the mandibular canal, grouped by sex and side

\begin{tabular}{|c|c|c|c|c|c|}
\hline \multirow{2}{*}{ 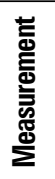 } & \multirow{2}{*}{$\begin{array}{l}\text { Coronal } \\
\text { section }\end{array}$} & \multicolumn{2}{|c|}{ Female } & \multicolumn{2}{|c|}{ Male } \\
\hline & & Left & Right & Left & Right \\
\hline \multirow[t]{5}{*}{$\mathrm{m} 1$} & $A$ & $16.2 \pm 2.7$ & $16.3 \pm 1.7$ & $17.8 \pm 4.0$ & $18.0 \pm 1.6$ \\
\hline & $B$ & $17.9 \pm 2$ & $17.9 \pm 2$ & $19.6 \pm 1.9$ & $19.1 \pm 1.9$ \\
\hline & $C$ & $16.7 \pm 1.9$ & $16.4 \pm 2.6$ & $18.3 \pm 1.7$ & $18.1 \pm 1.6$ \\
\hline & $D$ & $16.3 \pm 2.1$ & $16.4 \pm 2$ & $18.1 \pm 1.5$ & $17.6 \pm 2.1$ \\
\hline & $E$ & $17 \pm 2$ & $17.3 \pm 2$ & $18.4 \pm 1.5$ & $18.3 \pm 1.6$ \\
\hline \multirow[t]{5}{*}{$\mathrm{m} 2$} & $A$ & $3.2 \pm 0.8$ & $3.2 \pm 1.2$ & $3.4 \pm 1.0$ & $2.9 \pm 1.4$ \\
\hline & B & $3.8 \pm 1$ & $4.1 \pm 1.2$ & $3.9 \pm 1.2$ & $3.1 \pm 1.4$ \\
\hline & $C$ & $4.7 \pm 1$ & $4.7 \pm 1.3$ & $4.3 \pm 1.6$ & $4.0 \pm 1.1$ \\
\hline & $D$ & $5.2 \pm 1$ & $5 \pm 1.2$ & $5.1 \pm 1.2$ & $4.5 \pm 0.9$ \\
\hline & $E$ & $5.6 \pm 1.1$ & $5.6 \pm 1.4$ & $5.8 \pm 1.4$ & $5.2 \pm 0.9$ \\
\hline \multirow[t]{5}{*}{ m3 } & $A$ & $4.2 \pm 1.2$ & $4.6 \pm 2$ & $5.2 \pm 1.3$ & $5.0 \pm 2.1$ \\
\hline & B & $3.9 \pm 1.3$ & $3.7 \pm 1.3$ & $5.0 \pm 1.5$ & $4.5 \pm 1.8$ \\
\hline & $C$ & $3.3 \pm 1.3$ & $3.3 \pm 1.2$ & $4.2 \pm 1.6$ & $4.0 \pm 1.2$ \\
\hline & $D$ & $3 \pm 1.4$ & $2.9 \pm 1.1$ & $3.2 \pm 1.3$ & $3.5 \pm 1.2$ \\
\hline & $E$ & $2.6 \pm 1.3$ & $2.5 \pm 1.1$ & $2.8 \pm 1.5$ & $2.9 \pm 1.4$ \\
\hline \multirow[t]{5}{*}{ m4 } & A & $8.8 \pm 1.7$ & $8.4 \pm 1.6$ & $9.1 \pm 1.7$ & $9.3 \pm 2.4$ \\
\hline & B & $8.2 \pm 1.8$ & $8 \pm 2$ & $9.6 \pm 2.5$ & $9.7 \pm 2.2$ \\
\hline & $C$ & $7.9 \pm 1.8$ & $7.7 \pm 2$ & $9.0 \pm 2.7$ & $8.8 \pm 2.4$ \\
\hline & $D$ & $7.5 \pm 1.8$ & $7.5 \pm 1.9$ & $9.1 \pm 2.0$ & $9.0 \pm 2.9$ \\
\hline & $E$ & $7.3 \pm 1.8$ & $7.1 \pm 1.8$ & $8.5 \pm 2.3$ & $8.8 \pm 2.6$ \\
\hline \multirow[t]{5}{*}{ B1 } & $A$ & $2.4 \pm 0.4$ & $2.3 \pm 0.4$ & $2.6 \pm 0.6$ & $2.4 \pm 0.3$ \\
\hline & B & $2.4 \pm 0.3$ & $2.6 \pm 0.8$ & $2.5 \pm 0.3$ & $2.3 \pm 0.5$ \\
\hline & $C$ & $2.4 \pm 0.3$ & $2.4 \pm 0.3$ & $2.4 \pm 0.4$ & $2.3 \pm 0.3$ \\
\hline & $D$ & $2.5 \pm 0.4$ & $2.4 \pm 0.4$ & $2.4 \pm 0.4$ & $2.4 \pm 0.3$ \\
\hline & $E$ & $2.4 \pm 0.4$ & $2.5 \pm 0.4$ & $2.6 \pm 0.8$ & $2.4 \pm 0.3$ \\
\hline \multirow[t]{5}{*}{ B2 } & $A$ & $2.2 \pm 0.5$ & $2.5 \pm 1.0$ & $2.3 \pm 0.3$ & $2.4 \pm 0.2$ \\
\hline & B & $2.2 \pm 0.6$ & $2.1 \pm 0.3$ & $2.7 \pm 1.1$ & $2.4 \pm 0.6$ \\
\hline & $C$ & $2.1 \pm 0.5$ & $2.2 \pm 0.4$ & $2.1 \pm 0.5$ & $2.5 \pm 0.6$ \\
\hline & $D$ & $2.1 \pm 0.6$ & $2.0 \pm 0.4$ & $2.3 \pm 0.9$ & $2.2 \pm 0.4$ \\
\hline & $E$ & $2.0 \pm 0.5$ & $1.9 \pm 0.4$ & $1.9 \pm 0.5$ & $2.1 \pm 0.5$ \\
\hline \multirow[t]{5}{*}{ B3 } & $A$ & $3.9 \pm 0.8$ & $3.9 \pm 0.8$ & $4.3 \pm 0.6$ & $4.3 \pm 0.7$ \\
\hline & B & $3.9 \pm 0.7$ & $3.9 \pm 0.8$ & $4.0 \pm 1.2$ & $4.3 \pm 1.2$ \\
\hline & C & $3.9 \pm 0.6$ & $3.8 \pm 0.4$ & $4.3 \pm 1.0$ & $4.2 \pm 1.3$ \\
\hline & $D$ & $3.9 \pm 0.7$ & $3.8 \pm 0.6$ & $4.0 \pm 1.2$ & $4.3 \pm 1.2$ \\
\hline & $E$ & $3.8 \pm 0.7$ & $3.8 \pm 0.6$ & $4.2 \pm 0.9$ & $4.1 \pm 1.3$ \\
\hline \multirow[t]{5}{*}{$F$} & A & $88.9 \pm 5.6$ & $88.6 \pm 5.8$ & $91.4 \pm 5.4$ & $90.0 \pm 8.0$ \\
\hline & B & $87.0 \pm 5.8$ & $87.1 \pm 5.4$ & $89.9 \pm 6.0$ & $87.7 \pm 6.4$ \\
\hline & $C$ & $86.8 \pm 5.7$ & $87.6 \pm 5.7$ & $90.0 \pm 6.0$ & $87.8 \pm 6.8$ \\
\hline & $D$ & $86.6 \pm 6.6$ & $86.6 \pm 6.2$ & $89.4 \pm 5.8$ & $86.6 \pm 6.3$ \\
\hline & $E$ & $83.3 \pm 7.5$ & $84.0 \pm 7.3$ & $87.5 \pm 7.5$ & $84.9 \pm 6.7$ \\
\hline
\end{tabular}

between males and females $(p=0.160, p=0.916$, and $p=0.285$, respectively).

In section $D$ (sulcus of the first molar), the mean values of $\mathrm{m} 1$ and $\mathrm{m} 4$ were significantly greater in males than in females $(p=0.000$ and $p=0.000$, respectively). For the rest of the measurements (m2, m3, F, B1, B2, and B3), no significant differences were found between males and females $(p=0.193$, $p=0.063, p=0.263, p=0.994, p=0.196$, and $\mathrm{p}=0.072$, respectively).

Finally, in section $E$ (distal of the first molar), the mean value of $m 1$ was significantly greater in males than in females $(p=0.020)$. On the other hand, for the rest of the measurements ( $m 2, m 3, F, B 1, B 2$, and $B 3)$, no significant differences were found between males and females $(p=0.806, p=0.418, p=0.144$, $p=0.812, p=0.570$, and $p=0.108$, respectively).

In this study no significant differences were found in the measurements of any given section between the left and right sides of the mandible.

\section{Analysis of the morphometric relations of the MC in the mandibular body between the different coronal sections}

When the right hemiarch was analysed in males, only the mean value of $\mathrm{m} 2$ (distance to vestibular of the MC) showed significant differences between the different sections such that $A<D(p=0.008)$ and $E(p=0.000) ; B<D(p=0.009)$ and $E(p=0.000)$ and $C<E(p=0.012)$. In the case of $m 3$ (distance to lingual of the $M C$ ), significant differences were found between the sections such that $A>B>C>D>E$ ( $p=0.005$ in all cases). These two results suggest that the MC courses away from the vestibular cortical of the mandible and towards the lingual cortical, from anterior to posterior in the mandibular body. Likewise for B2 (thickness of the mandibular lingual cortical) significant differences were found between the sections such that $A>B>C>D>E(p=0.033$ in all cases), showing thinning of the cortical to posterior.

When the left hemiarch was analysed as above in males, the mean value of $\mathrm{m} 2$ showed significant differences between the different sections such that $A<D(p=0.016)$ and $E(p=0.000) ; B<E(p=0.000)$ and $C<E(p=0.004)$. This indicates that the MC courses away from the vestibular cortical of the mandible from anterior to posterior in the mandibular body. Likewise for B2 significant differences were found between the different sections ( $p=0.025)$, such that the mean values of sections $A, B$ and $C$ 
were the highest $(2.3 \pm 0.3 \mathrm{~mm}, 2.7 \pm 1.1 \mathrm{~mm}$ and $2.3 \pm 0.5 \mathrm{~mm}$, respectively).

When the right hemiarch was analysed in females, the mean value of $m 1$ (distance to superior of the MC) showed significant differences between the different sections such that $B<C(p=0.042)$ and $B<D$ $(p=0.043)$. This suggests that the MC is more distant from the alveolar crests in the zone of the first molar. Likewise $\mathrm{m} 2$ presented significant differences between the different sections such that $A<C(p=0.001)$, $D(p=0.000)$ and $E(p=0.000) ; C<E(p=0.029)$ and $B<E(p=0.000)$. This suggests that the $M C$ courses away from the vestibular cortical of the mandible from anterior to posterior in the mandibular body.

Finally when the left hemiarch was analysed in females, significant differences were found between the sections for $m 1$, with the highest mean values in sections $B, C$ and $E(p=0.000, p=0.030$ and $p=0.001$, respectively). In the case of $m 2$, significant differences were found between the different sections such that $A>B>C>D>E$ ( $p=0.000$ in all cases). For $m 3$, significant differences were also found between the different sections such that $A>B>C>D>E(p=0.000$ in all cases). These two results indicate that the MC courses away from the vestibular cortical of the mandible and towards the lingual cortical, from anterior to posterior in the mandibular body. Finally, for $\mathrm{m} 4$ and $\mathrm{F}$ significant differences were found such that $A>E(p=0.035$ and $p=0.041$, respectively for each measurement).

\section{DISCUSSION}

Carrying out highly complex and invasive procedures in the mandible requires the dentist to be familiar with all the anatomical structures in the area of the intervention site. Thus analysing the anatomical course and relations of the $\mathrm{MC}$ represents one of the most important tasks for the clinician intervening in this zone. CBCT has proved to be a valuable support tool for the planning and programming of these challenging treatments, since it is a very sensitive means of locating and identifying the $M C[2,11]$. CBCT provides the clinician with the necessary information on the thickness, dimension and location of the $\mathrm{MC}$ in relation to other structures [12], allowing damage to be avoided to the vasculo-nervous bundle which runs close to the tooth roots [1]. CBCT has been reported to be very superior to panoramic radiography in both specificity and sensitivity $[3,23]$. When panoramic radiography is used, it has to be borne in mind that it presents a certain discrepancy in the thickness of the structures [18].
The locations observed in our study for the emergence of the $M C$ are very similar to those reported by other authors $[6,7,25]$, with the mental foramen found in the area between the first and second premolars. In all the hemiarches examined in our study, the mental foramen was found to medial of the mesial root of the first molar.

In our study, CBCT was used to assess the morphometric relations of the course of the MC within the mandibular body of dentate subjects. To do this, distance relations were established with the alveolar crests and the mandibular corticals (vestibular, lingual and basal), and the thicknesses of the cortical bones of the mandibular body were also reported. Our results indicate that to distal of the first molar, the $M C$ describes a sinuous course approaching the lingual cortical of the mandible. This is confirmed by the findings of Muñoz et al. [16], who described the location of the MC, viewed frontally towards the coronal section of the mandibular body, as coursing closer to the lingual cortical towards the retromolar space. Other authors, such as Dominguez et al. [4], who analysed CBCTs, and Sîrbu et al. [22], who analysed CBCTs and dry mandibles, also reported similar results. In our analysis, none of the morphometric measurements or relations of the $\mathrm{MC}$ indicating its location with respect to the corticals of the mandibular body presented any significant differences between the left and right hemiarches, either in males or females. This finding should be compared with that of Kawashima et al. [10], who reported that the distance between the MC and the vestibular cortical of the mandible (vestibular thickness) was significantly smaller in the right side than the left, in both males and females.

Our results also indicate that, in females at least, the MC courses at a greater depth (further from the alveolar crests) in the molar zone; this may coincide with the findings reported by Sirbu et al. [22], who described a descendant trajectory from the second molar towards the first molar and then slightly ascendant towards the second premolar. It should be noted that in classical descriptions the course of the MC in this area is described as coursing obliquely downwards and forwards towards the region of the premolars [5].

\section{CONCLUSIONS}

Our results contribute to characterisation of the course of the MC in the mandibular body, which may vary depending on the characteristics of the population and the state of individual dentition. The 
MC presents an antero-posterior course which could be considered oblique from vestibular to lingual and sinuous in the supero-inferior plane, as it deviates away from the alveolar crests in the molar zone. In general, the course of the MC is similar in both hemiarches of the mandible, although population-related differences may exist. Finally the thicknesses of the mandibular body measured from the corticals to the MC were found to be consistently greater in males than females; however, it must be considered that age may play a determining role in this respect.

\section{REFERENCES}

1. Aksoy U, Aksoy S, Orhan K. A cone-beam computed tomography study of the anatomical relationships between mandibular teeth and the mandibular canal, with a review of the current literature. Microsc Res Tech. 2017; 81(3): 308-314, doi: 10.1002/jemt.22980, indexed in Pubmed: 29285826.

2. Angelopoulos $\mathrm{C}$, Thomas SL, Thomas S, et al. Comparison between digital panoramic radiography and cone-beam computed tomography for the identification of the mandibular canal as part of presurgical dental implant assessment. J Oral Maxillofac Surg. 2008; 66(10): 2130-2135, doi: 10.1016/j. joms.2008.06.021, indexed in Pubmed: 18848113.

3. Azcárate-Velázquez F, Bertos-Quilez J, Marmesat-Guerrero F, et al. Fiabilidad del uso de la tomografía computarizada de haz cónico en la localización y medida del conducto mandibular en la planificación de técnicas quirúrgicas en el cuerpo mandibular. Revista Española de Cirugía Oral y Maxilofacial. 2015; 37(4): 182-187, doi: 10.1016/j. maxilo.2014.03.003.

4. Domínguez J, Ruge O, Aguilar G, et al. Análisis de la posición y trayectoria del conducto alveolar inferior (CAI) en tomografía volumétrica computarizada (TC Cone Beam - TCCB). Rev Fac Odontol Univ Antioq. 2010; 22(1): 12-22.

5. Figún $M$, Garino R. Anatomía Odontológica Funcional y Aplicada. 2da ed. El Ateneo, Buenos Aires. 2001.

6. Fuentes R, Flores T, Dias F, et al. Localization of the mental foramen through digital panoramic radiographs in a chilean population. Int J Morphol. 2017; 35(4): 1309-1315, doi: 10.4067/s0717-95022017000401309.

7. Gungor E, Aglarci OS, Unal M, et al. Evaluation of mental foramen location in the 10-70 years age range using conebeam computed tomography. Niger J Clin Pract. 2017; 20(1): 88-92, doi: 10.4103/1119-3077.178915, indexed in Pubmed: 27958253.

8. Haas LF, Dutra K, Porporatti AL, et al. Anatomical variations of mandibular canal detected by panoramic radiography and CT: a systematic review and meta-analysis. Dentomaxillofac Radiol. 2016; 45(2): 20150310, doi: 10.1259/ dmfr.20150310, indexed in Pubmed: 26576624.

9. Karamifar K, Shahidi S, Tondari A. Bilateral bifid mandibular canal: report of two cases. Indian J Dent Res. 2009; 20(2): 235-237, doi: 10.4103/0970-9290.52889, indexed in Pubmed: 19553729.

10. Kawashima Y, Sakai O, Shosho D, et al. Proximity of the mandibular canal to teeth and cortical bone. J Endod. 2016; 42(2): 221-224, doi: 10.1016/j.joen.2015.11.009, indexed in Pubmed: 26725176.
11. Kilic C, Kamburoğlu K, Ozen T, et al. The position of the mandibular canal and histologic feature of the inferior alveolar nerve. Clin Anat. 2010; 23(1): 34-42, doi: 10.1002/ ca.20889, indexed in Pubmed: 19918867.

12. Koivisto T, Chiona D, Milroy LL, et al. Mandibular canal location: cone-beam computed tomography examination. J Endod. 2016; 42(7): 1018-1021, doi: 10.1016/j. joen.2016.03.004, indexed in Pubmed: 27178249.

13. Kuczynski A, Kucharski W, Franco A, et al. Prevalence of bifid mandibular canals in panoramic radiographs: a maxillofacial surgical scope. Surg Radiol Anat. 2014; 36(9): 847-850, doi: 10.1007/s00276-014-1298-2, indexed in Pubmed: 24752397.

14. Mizbah K, Gerlach N, Maal TJ, et al. The clinical relevance of bifid and trifid mandibular canals. Oral Maxillofac Surg. 2012; 16(1): 147-151, doi: 10.1007/s10006-011-0278-5, indexed in Pubmed: 21698363.

15. Montaño M. Tomografia cone beam 3D su aplicación en odontología. Rev Act Clin Med. 2013; 38(38): 1897-1901.

16. Muñoz G, Dias F, Weber B, et al. Anatomic relationships of mandibular canal. A cone beam CT study. Int J Morphol. 2017; 35(4): 1243-1248, doi: 10.4067/s071795022017000401243.

17. Nortjé CJ, Farman AG, Grotepass FW. Variations in the normal anatomy of the inferior dental (mandibular) canal: A retrospective study of panoramic radiographs from 3612 routine dental patients. Br J Oral Surg. 1977; 15(1): 55-63, doi: 10.1016/0007-117x(77)90008-7.

18. Oliveira-Santos C, Capelozza AL, Dezzoti MS, et al. Visibility of the mandibular canal on CBCT cross-sectional images. J Appl Oral Sci. 2011; 19(3): 240-243, doi: 10.1590/s167877572011000300011 , indexed in Pubmed: 21625740.

19. Roa I, Arriagada O. Variaciones del canal mandibular con importancia clínica: reporte de caso. Int J Morphol. 2015; 33(3): 971-974, doi: 10.4067/s071795022015000300026.

20. Rouvière $H$, Delmas $A$. Anatomía Humana Descriptiva, Topográfica y Funcional. 10a ed. Masson, Barcelona. 1999.

21. Sánchez B, Díaz J, Villanueva-Vilchis $M$, et al. Morphometric relationships between the mandibular canal and the molar teeth: a tomographic analysis report. Int J Morphol. 2017; 35(2): 564-570, doi: 10.4067/s071795022017000200030.

22. Sîrbu VD, Perlea P, Nimigean VR, et al. Morphological assessment of the mandibular canal trajectory in dentate subjects. Rom J Morphol Embryol. 2017; 58(4): 1401-1408, indexed in Pubmed: 29556634.

23. Tantanapornkul W, Okouchi K, Fujiwara $Y$, et al. A comparative study of cone-beam computed tomography and conventional panoramic radiography in assessing the topographic relationship between the mandibular canal and impacted third molars. Oral Surg Oral Med Oral Pathol Oral Radiol Endod. 2007; 103(2): 253-259, doi: 10.1016/j. tripleo.2006.06.060, indexed in Pubmed: 17234544.

24. White S, Pharoah M. Oral Radiology Principles and Interpretation. 7a ed. Elseiver, Riverport Ln. 2014.

25. Zmyslowska-Polakowska E, Radwanski M, Ledzion S, et al. Evaluation of Size and Location of a Mental Foramen in the Polish Population Using Cone-Beam Computed Tomography. Biomed Res Int. 2019; 2019: 1659476, doi: 10.1155/2019/1659476, indexed in Pubmed: 30719439. 